\title{
VALIDATION OF THE ANALYTICAL METHOD FOR THE DETERMINATION OF FLAVONOIDS IN BROCCOLI
}

\author{
Magdalena TUSZYŃSKA \\ Research Institute of Horticulture \\ Konstytucji 3 Maja 1/3, 96-100 Skierniewice, Poland \\ Received: October 26, 2013; Accepted: May 15, 2014
}

\begin{abstract}
A simple, accurate and selective HPLC method was developed and validated for determination of quercetin and kaempferol, which are the main flavonols in broccoli. The separation was achieved on a reversed-phase $C_{18}$ column using a mobile phase composed of methanol/water (60/40) and phosphoric acid $0.2 \%$ at a flow rate of $1.0 \mathrm{ml} \cdot \mathrm{min}^{-1}$. The detection was carried out on a DAD detector at $370 \mathrm{~nm}$. This method was validated according to the requirements for new methods, which include selectivity, linearity, precision, accuracy, limit of detection and limit of quantitation. The current method demonstrates good linearity, with $\mathrm{R}^{2}>0.99$. The recovery is within $98.07-102.15 \%$ and $97.92-101.83 \%$ for quercetin and kaempferol, respectively. The method is selective, in that quercetin and kaempferol are well separated from other compounds of broccoli with good resolution. The low limit of detection and limit of quantitation of quercetin and kaempferol enable the detection and quantitation of these flavonoids in broccoli at low concentrations.
\end{abstract}

Key words: quercetin, kaempferol, broccoli, validation

\section{INTRODUCTION}

Recognition of diet as a primary causative factor for cancer risk has directed much research attention toward the chemoprotective role of certain compounds in foods. Human diet offers a greater and more diverse group of plant bioactives than do drugs. People often do not realise that many drugs are derived from the compounds originally discovered in plant foods.

Recent epidemiological studies have indicated that an increased uptake of dietary Brassica vegetables in general, and broccoli in particular, may protect humans against cancer and cardiovascular diseases (Manach et al. 2005, Rossi et al. 2007) because they are rich sources of glucosinolates, flavonoids, vitamins and mineral nutrients (Perez-Vizcaino et al. 2006).

Flavonoids are part of a large group of naturally occurring plant phenolics. They occur in plants mainly as glycosides - conjugates of several types of aglycones with carbohydrates. Flavonoids are particularly interesting as they are potent in vitro antioxidants (Duthie \& Crozier 2000, Pietta 2000), display free radical scavenging activity (Van Acker et al. 1995), induce protective enzymes (Nijveldt et al. 2001) and are thought to play key roles in many of the processes underlying vascular dysfunction and the development of atherosclerosis (Schroeter et al. 2006). Antibacterial, antithrombotic, antinflammatory and anticarcinogenic properties of flavonoid compounds have also been reported in many reviews (Erlund 2004, Middleton et al. 2000, Steinmetz $\&$ Potter 1996). The flavonoids in brassicas are present as flavonols, a subgroup within the flavonoid family. The main flavonols in broccoli are kaempferol and quercetin, both of them exist as conjugated structures (Fig. 1). In general, their levels depend on many factors including: cultivar (Vallejo et al. 2002), environmental pressures (Dixon \& Paiva 1995), post-harvest transport, handling and storage conditions (Vallejo et al. 2003). 


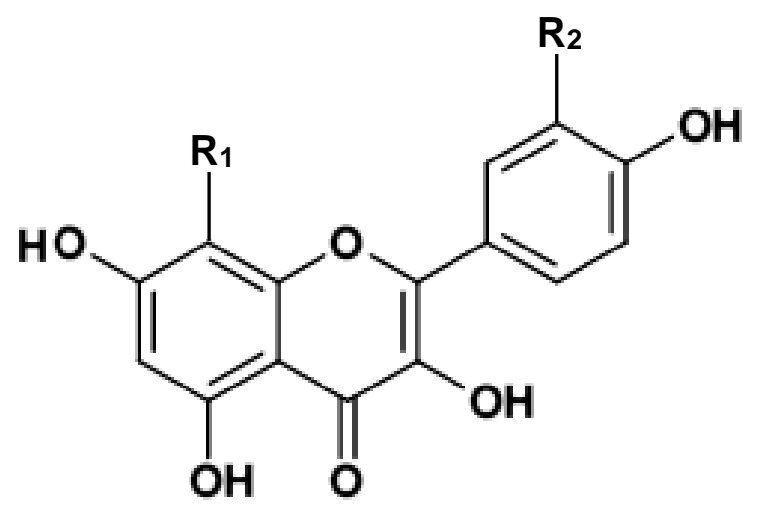

\begin{tabular}{lcc}
\hline & $\mathrm{R}_{1}$ & $\mathrm{R}_{2}$ \\
\hline Quercetin & $\mathrm{H}$ & $\mathrm{OH}$ \\
\hline Kaempferol & $\mathrm{H}$ & $\mathrm{H}$ \\
\hline
\end{tabular}

Fig. 1. Structures of main flavonol aglycones found in the broccoli extracts

The health benefits associated with consumption of dietary flavonoids have led to an increased interest in the study of these vegetables and analytical techniques used to precisely determine flavonoid contents. Conventional liquid extraction methods, e.g. water bath or ultrasonication, with aqueous methanol or acetonitrile have been widely used as simple and easy methods in analysis of flavonoids (Robards 2003). Extraction of flavonoid aglycones has most often been done by acid hydrolysis (Sellappan \& Akoh 2002; Nuutila et al. 2002), but harsh extraction conditions should be avoided if intact flavonoid glycosides are desired (de Rijke et al. 2006). Mostly, spectrophotometric and chromatographic methods, and in particular high performance liquid chromatography (HPLC), have been used to determine the flavonoids contents (Gliszczyńska-Świgło et al. 2006, Roy et al. 2009). Price et al. (1998) used a combination of degradative chemistry, HPLC with diode array detection (DAD), mass spectrometry (MS) and nuclear magnetic resonance to investigate the structures of five flavonol glycosides present in broccoli. Koh et al. (2009) used HPLC to quantitatively determine the kaempferol and quercetin content in 80 commercial broccoli samples. Following acid hydrolysis the kaempferol and quercetin levels were measured and ranged from 2.4 to 132.0 and from 0.3 to $108.5 \mathrm{mg} \cdot \mathrm{kg}^{-1}$ fresh weight, respectively.
Users of every analytical method must make sure that the results obtained in their laboratory are fit for their purpose. This means that analytical requirements must be defined and values of the performance parameters assessed before they are used as the routine method in the laboratory. Therefore, analytical methods must be validated. The ISO/IEC 17025 standard defines method validation as a "confirmation with an examination and provision of objective evidences that the particular requirements for a specified use are met'. So the first thing to be done is to define these particular requirements that depend on the specific determination ahead. The validation should be sufficiently large in so far as it is necessary for a specific application. Note, however, that validation is always a compromise between cost, risk and technical capabilities.

The aim of the study was validation of the HPLC method for flavonols analysis based on the procedure described by Patil et al. (1995) and Horbowicz (1999). The method was modified for the determination of flavonols in broccoli. If a method is modified or applied to a new situation (e.g. different sample matrix), revalidation or verification would be required depending on the extent of the modification and the nature of new situation. No action is required where a modification is only small, for example when a chromatographic column is changed for another of the same type.

\section{MATERIALS AND METHODS}

\section{Plant material and chemicals}

The analytical standards of quercetin and kaempferol were purchased from Sigma-Aldrich (Germany), methanol HPLC, orthophosphoric acid $85 \%$ pure p.a. and hydrochloric acid $35-38 \%$ pure p.a. were purchased from Chempur (Poland). Fresh broccoli (Brassica oleracea L. var. italica Plenck, cvs Grand Prix and Kuba) heads delivered by PRIMAVEGA - Group of Vegetable Growers company were stored at $4{ }^{\circ} \mathrm{C}$ and used within $24 \mathrm{~h}$. Heads of broccoli, about 300-400 g each, were selected for absence of visual defects and uniform colour and separated in single florets using a sharp knife. A stock solution of kaempferol and quercetin was prepared by dissolving an appropriate amount of each compound in $100 \% \mathrm{MeOH}$. From the stock 
solution, phenolic standards in the range of $0.3-$ $43.0 \mathrm{ppm}$ were prepared in $60 \% \mathrm{MeOH}$.

\section{Extraction and isolation of phenolic compounds}

After preparation, broccoli florets $(2 \mathrm{~cm}$ diam.) were packaged into PE bags and air-frozen at temperature $-25{ }^{\circ} \mathrm{C}$. Samples of broccoli before flavonoid analysis were lyophilised and homogenised. A $200 \mathrm{mg}$ portions were taken to analyses. Glycoside forms of flavonoids were extracted from broccoli with $8 \mathrm{ml} 62.5 \%$ aqueous methanol in an ultrasonic bath for $20 \mathrm{~min}$. Extracted glycosides were subjected to hydrolysis in $2 \mathrm{ml} 2 \mathrm{M} \mathrm{HCl}$. Hydrolysis conditions were following: temperature $90{ }^{\circ} \mathrm{C}$ and time $30 \mathrm{~min}$. The hydrolysed sample was cooled to room temperature, made up to $20 \mathrm{ml}$ with methanol and sonicated for $5 \mathrm{~min}$. The extract was filtered through $0.5 \mu \mathrm{m}$ disposable filters (Supelco Analytical). $100 \mu \mathrm{l}$ of clear supernatants were taken to analysis.

\section{Chromatographic conditions and apparatus}

Flavonoids were separated and quantified using an Agilent Technologies 1200 Series HPLC equipped with a diode array detector DAD G1315B. Chromatographic conditions were developed as follows. The optimised separation method using Zorbax Eclipse XDB-C18 column $(4.6 \times 150 \mathrm{~mm}$, $5 \mu \mathrm{m}$ particle size, Agilent, Palo Alto, CA, USA) to identify kaempferol and quercetin. The mobile phase consisted of a mixture of methanol-water (60:40) acidified with $0.2 \%$ of orthophosphoric acid, filtered and degassed by suction-filtration through a nylon membrane, in isocratic flow. The HPLC system was operated at flow-rate of $1 \mathrm{ml} \cdot \mathrm{min}^{-1}$ and temperature of the column was set at $25{ }^{\circ} \mathrm{C}$. The sample injection volume was $20 \mu \mathrm{l}$ and the flavonoids were detected at $370 \mathrm{~nm}$. The separated flavonoid peaks were identified by comparing with the retention time of individual standards peaks.

\section{Optimisation of acid hydrolysis}

The acid hydrolysis is a commonly used method for the conversion of glycosides to aglycones. It is a simple, rapid and cost-effective method. Hertog et al. (1992) determined the flavonoid contents in a range of fruit and vegetables after acid hydrolysis under different conditions of acid concentrations and reaction times. The study demonstrated that optimal hydrolysis conditions varied for each food sample and hydrolysis conditions must be tailored to suit individual foods. The concentration of $\mathrm{HCl}$, hydrolysis time and temperature were investigated to obtain the flavonoids aglycones. The phenolic extracts of broccoli were subjected to hydrolysis by $\mathrm{HCl}$ of 1,2 , 3,4 and $5 \mathrm{M}$ at $90{ }^{\circ} \mathrm{C}$ for $30 \mathrm{~min}$. The hydrolysed samples were cooled, filtered and subjected to HPLC analysis. Similarly, $8 \mathrm{ml}$ of extract solution was hydrolysed with $2 \mathrm{ml} 2 \mathrm{M} \mathrm{HCl}$ at different temperatures $\left(80,90\right.$ and $\left.100{ }^{\circ} \mathrm{C}\right)$ for $30 \mathrm{~min}$. The extract $(8 \mathrm{ml})$ was also hydrolysed with $2 \mathrm{ml}$ of $2 \mathrm{M} \mathrm{HCl}$ at $90{ }^{\circ} \mathrm{C}$ for different times $(15,30,60$ and $120 \mathrm{~min}$ ). The effect of antioxidant was also tested. Ascorbic acid was added prior to hydrolysis at concentrations of 4,8 and $12 \mathrm{mg}$.

\section{Optimisation of the chromatographic conditions}

Before selecting the conditions for the optimisation, a number of preliminary trials were conducted with different ratios of solvents, flow rate and working temperatures in order to check the retention time, peaks shape and other chromatographic parameters. The effectiveness of the HPLC method was tested using standard solutions of quercetin and kaempferol. Water and methanol mixtures are most often chosen as an eluant, but acetonitrile, ethanol and formic acid are also reported. Water and methanol were selected for the developed method. Different concentration of this solvent and temperatures of column were subsequently tested to achieve the best resolution of examined analytes.

\section{Method validation}

A validation study was carried out to demonstrate the applicability of this analytical approach. Validation comprised the assessment of specificity/selectivity, linearity, recovery, precision and the limits of detection (LODs) and quantification (LOQs).

The International Conference on Harmonisation of Technical Requirements for Registration of Pharmaceuticals for Human Use (ICH) defines specificity as 'the ability to assess unequivocally the analyte in the presence of components which may be expected to be present. Typically this might 
include impurities, degradants, matrix, etc. The other reputable authorities such as International Union of Pure and Applied Chemistry (IUPAC) and AOAC INTERNATIONAL use the term 'selectivity' for the same meaning. This reserves the use of 'specific' for those procedures that produce a response for a single analyte only. Specificity in liquid chromatography is obtained by choosing optimal columns and setting chromatographic conditions such as mobile phase composition, column temperature and detector wavelength. Besides chromatographic separation, the sample preparation step can also be optimised for best selectivity.

The specificity of our method was evaluated through the analysis of samples spiked with each flavonoid standard separately, and of samples spiked with a mixture of quercetin and kaempferol standards. The specificity of the validated method has been already determined during optimisation of the analyte determination conditions where the para-meters selection has been carried out in such a way that the components separation was the best, and the influence of interfering factors was the lowest.

To evaluate the linearity of the method, the calibration curves were plotted by peak area versus concentration of each flavonoid. To prepare the standard solutions, quercetin $(0.31,0.63,1.25,2.5$, 5.0, 10.0, 12.5 and $\left.25.0 \mu \mathrm{g} \cdot \mathrm{ml}^{-1}\right)$ and kaempferol $(0.27,0.54,1.08,2.15,4.3,10.8,21.6$ and $43.2 \mu \mathrm{g} \cdot \mathrm{ml}^{-1}$ ) were dissolved in methanol. The linear regression equations were calculated as $y=a x \pm b$, where $x$ was concentration and $y$ was the peak areas of each flavonoid. The acceptance criterion for linearity is that the correlation coefficient $\left(\mathrm{R}^{2}\right)$ should not be less than 0.990 over the working range $80-120 \%$ (Australian Pesticides and Veterinary Medicines Authority - APVMA, 2004; ICH 2005). Limits of detection (LODs) and quantification (LOQs) were determined based on the standard deviation of the response and the slope, using the calibration curve data. Analysis was performed in triplicate.

Accuracy was evaluated by determining the method recovery. According to APVMA the accuracy should cover at least three concentrations $(80$,
100 and $120 \%$ ) in the expected range. The mean percentage of recovery should be within the following ranges.

Table 1. Expected recovery as a function of analyte concentration

\begin{tabular}{cc}
\hline $\begin{array}{c}\text { Active/impurity } \\
\text { content }(\%)\end{array}$ & $\begin{array}{c}\text { Acceptable mean } \\
\text { recovery }(\%)\end{array}$ \\
$\geq 10.0$ & $98-102$ \\
$\geq 1.0$ & $90-110$ \\
$0.1-1.0$ & $80-120$ \\
$<0.1$ & $75-125$ \\
\hline
\end{tabular}

The accuracy experiments were performed applying the method to quantify quercetin and kaempferol. Analysed samples were spiked with known amounts of flavonoid standards. Three different amounts of quercetin $(285.00,355.00$ and $430.00 \mu \mathrm{g})$ and kaempferol $(225.00,280.00$ and $335.00 \mu \mathrm{g}$ ) were added to broccoli samples. The mixture was hydrolysed as mentioned above and injected into HPLC. The percent recovery of each flavonoid from spiked samples was calculated as follows:

$$
\begin{gathered}
\% \text { Recovery }=(\text { Amount of flavonoid after } \\
\text { spiking } \times 100) /(\text { Original concentration } \\
\text { of flavonoid }+ \text { spiked amount }) \\
\% \text { RSD }=(\text { Standard deviation of flavonoid } \\
\times 100) /(\text { Average content of flavonoid })
\end{gathered}
$$

The precision of the intra- and inter-day was evaluated by the repeated injection. The intra-day experiment was obtained by six replicates for a day, and the inter-day was determined by six injections for 3 days for the peak area. The precision was expressed as relative standard deviation (RSD, \%). The following levels of precision are recommended by APVMA.

Table 2. Expected precision as a function of analyte concentration

\begin{tabular}{cc}
\hline $\begin{array}{c}\text { Component measured in } \\
\text { sample }(\%)\end{array}$ & Precision $(\%)$ \\
$\geq 10.0$ & $\leq 2$ \\
$1.0-10.0$ & $\leq 5$ \\
$0.1-1.0$ & $\leq 10$ \\
$<0.1$ & $\leq 20$ \\
\hline
\end{tabular}




\section{RESULTS AND DISCUSSION}

\section{Optimisation of acid hydrolysis}

The hydrolysis of flavonoid glycosides needs optimisation of the hydrochloric acid concentration, hydrolysis time and temperature. The extract was hydrolysed with various concentrations of $\mathrm{HCl}$ (Fig. 2A). The quercetin and kaempferol content was the highest at hydrolysis with $2 \mathrm{M} \mathrm{HCl}$ and decreased in the order of acid $3>4>1>5 \mathrm{M} \mathrm{HCl}$. Moreover, the efficient hydrolysis time was investigated (Fig. 2B). The highest content of quercetin and kaempferol was found after 30 min of hydrolysis. The levels of quercetin and kaempferol were higher at $90{ }^{\circ} \mathrm{C}$ than 80 and $100{ }^{\circ} \mathrm{C}$ (Fig. 2C). On the basis of the above results, we have used $2 \mathrm{M}$ $\mathrm{HCl}$, at $90{ }^{\circ} \mathrm{C}$ for $30 \mathrm{~min}$ for the quantification of flavonoids in broccoli. Higher concentration of $\mathrm{HCl}$ and reaction temperature, as well as longer hydrolysis time tended to result in a decrease of flavonoids content.

Degradation of quercetin, due to increasing reaction time, has also been reported by Hertog et al. (1992). It has not determined the necessity for the use of antioxidants in each case. There was no significant effect of 4, 8 and $12 \mathrm{mg}$ of ascorbic acid application on flavonoids content in broccoli samples. In recent years, some new methods of flavonoids hydrolysis have been developed, e.g. enzymatic hydrolysis. However, enzymatic hydrolysis requires longer times, from $16 \mathrm{~h}$ to several days. Acid hydrolysis method, which have been used for many decades are not time consuming.

\section{Optimisation of the HPLC method}

In order to investigate the effect of three HPLC variables (i.e. mobile phase, temperature and flow rate) on the detection value of flavonoids from broccoli isocratic elution was chosen. The mobile phase composition with different ratio of $\mathrm{MeOH} / \mathrm{H}_{2} \mathrm{O}$, temperature and flow rate was tested and the results were compared. Methanol was used as an organic modifier of the mobile phase in the chromatographic system, while no separation of quercetin was achieved when using acetonitrile, in accordance with the method reported by Hertog et al. (1992).
The peak area of quercetin and kaempferol was considered as response variables in this optimisation study. The ratio of solvents was as follows: $\mathrm{MeOH} / \mathrm{H}_{2} \mathrm{O} 50: 50,55: 45,60: 40$ and $70: 30$. The differences between retention times of quercetin and kaempferol were marked with changes of volume of methanol in the solution.


Fig. 2. Conversion of flavonoid glycosides to aglycones using different concentration of hydrochloric acid (A), hydrolysis time (B) and temperature (C). The values on Y1-axis correspond to kaempferol content and the values on Y2-axis correspond to quercetin content 
The decreasing ratio of methanol in the mobile phase evoked prolongation of the retention times of quercetin and kaempferol (from $R_{\mathrm{t}}=4.3 \mathrm{~min}$ at $70 \%$ $\mathrm{MeOH}$ to $R_{\mathrm{t}}=9.5 \mathrm{~min}$ at $50 \% \mathrm{MeOH}$ for querce-tin and from $R_{\mathrm{t}}=6.8 \mathrm{~min}$ at $70 \% \mathrm{MeOH}$ to $R_{\mathrm{t}}=15.9 \mathrm{~min}$ at $50 \% \mathrm{MeOH}$ for kaempferol). One serious problem in the separation of flavonoids was peak tailing, which has been connected with dissociation of the hydroxyl groups. The presence of acid in a mobile phase can prevent this effect by changing the $\mathrm{pH}$, hence improving peak symmetry of analytes ( $\mathrm{Zu}$ et al. 2006). The influence of different concentrations of orthophosphoric acid in the mobile phase and in the standard solution was tested. The solutions containing $0.1,0.2$ and $0.5 \%$ of orthophosphoric acid were studied. The best results were achieved with mobile phase $\mathrm{MeOH} / \mathrm{H}_{2} \mathrm{O} 60$ : 40 containing $0.2 \%$ of orthophosphoric acid. The methanol-water isocratic system containing $0.2 \%$ orthophosphoric acid resulted in the best separation at a flow rate of $1 \mathrm{ml} \mathrm{min}^{-1}$ and temperature of column of $25^{\circ} \mathrm{C}$. Under the conditions adopted, quercetin and kaempferol were fully separated after 8 min with good shaped peaks. Retention times for quercetin and kaempferol in samples were $4.834 \pm 0.009 \mathrm{~min}$ and $7.721 \pm 0.011 \mathrm{~min}$, respectively. Quercetin and kaempferol showed lower retention times than those generally reported in the literature (Merken \& Beecher 2000, Schieber et al. 2001, Sousa de Brito et al. 2007).

\section{Method validation}

After optimisation of the acid hydrolysis and the chromatographic conditions, the method was validated in terms of specificity/selectivity, linearity, recovery, precision and limits of detection (LODs) and quantification (LOQs). A validation study was carried out to demonstrate the method's performance.

The specificity of the method was evaluated by spiking the same broccoli samples with each of eight increasing concentrations of standard solutions within the concentration range, in duplicate.

The system response was examined through the presence of interference with the quercetin or kaempferol responses. The specificity of the analytical approach was confirmed because no interferences were demonstrated by using HPLC as described above. No other significant peaks with a signal-to-noise ratio of three or more were observed at the specific retention times of the quercetin and kaempferol, suggesting a high specificity of the analytical method. Acceptance criteria for test specificity have been met. Furthermore, the method presents a linear response between added concentration and peak area for these compounds; therefore it should be considered specific. Representative chromatograms of mixture of quercetin and kaempferol standards and broccoli sample are shown in Fig. 3.

Table 3 shows the data from the calibration curves for quercetin and kaempferol fitted by plotting concentration versus the corresponding mean peak area. The linearity was tested with eight different concentrations according to the expected levels in broccoli samples, over the range of 0.31$25.00 \mu \mathrm{g} \cdot \mathrm{ml}^{-1}$ and $0.27-43.2 \mu \mathrm{g} \cdot \mathrm{ml}^{-1}$ for quercetin and kaempferol, respectively. Satisfactory linearity was detected for both flavonoids in over the range. The least square regression showed excellent correlation, higher than 0.99 , which is considered highly significant for the method.

Table 3. Linearity, limits of detection, limits of quantification

\begin{tabular}{ccc}
\hline & Quercetin & Kaempferol \\
\hline $\begin{array}{c}\text { Concentra- } \\
\text { tion range }\end{array}$ & $0.31-25 \mu \mathrm{g} \cdot \mathrm{ml}^{-1}$ & $0.27-43.2 \mu \mathrm{g} \cdot \mathrm{ml}^{-1}$ \\
Equation & $y=84.679 x+18.403$ & $y=101.430 x+10.804$ \\
$\mathrm{R}^{2}$ & 0.9979 & 0.9995 \\
LOD & 0.0389 & 0.0325 \\
LOQ & 0.1178 & 0.0985 \\
\hline
\end{tabular}

The calculations for the limits of detection (LOD) were based on standard deviation of $y$-intercepts of the regression lines (SD) and the slope (S), using the equation LOD $=3.3(\mathrm{SD} / \mathrm{S})$. Limits of quantification (LOQ) were calculated by the equation $\mathrm{LOQ}=10(\mathrm{SD} / \mathrm{S})$. The obtained values for LOD and LOQ are given in Table 3. The values remain quite similar for both quercetin and kaempferol. These values were lower to those reported by other authors, working with conventional RP C18 columns and diode-array detection (Merken $\&$ Beecher 2000, Rodríguez-Delgado et al. 2001). Moreover, sensitivity was better than those found by Repollés et al. (2006), who worked with the monolithic column and ternary gradient elution. 



Fig. 3. Representative HPLC chromatograms of (A) standard solutions; (B) real sample of broccoli

The accuracy of the method was assessed by performing the recovery study. It was conducted by adding known amount of flavonoid standards.
The recovery was $98.07-102.15 \%$ for quercetin and 97.92-101.83\% for kaempferol (Table 4). The relative standard deviation (RSD) determines the precision and stability of the methods. The percentage of RSD of the average recovery was $0.94 \%$ for quercetin and $1.07 \%$ for kaempferol.

For the instrumental precision, intra-day (on the same day) and inter-day (on the three different days) precision was determined. The intra-day experiment was obtained by three replicates for a day, and the inter-day was determined by three injections for 3 days for the peak area. The precision was expressed as relative standard deviation (RSD, \%). The intra- and inter-day precisions presented RSD values lower than $2 \%$ for both quercetin and kaempferol, which were considered satisfactory for the purpose of the analysis.

Recently, reports suggesting beneficial nutritional and physiological effects of flavonoids have increased interest in vegetables as an important source of bioactive plant phenolics. It seems clear that there is no single suitable method for hydrolysis and analysis of flavonoids from any plant material. Different plant materials contain different flavonoids in different forms, resulting in variable susceptibility to degradation. For the samples used in this study, the 30 min refluxing at $90^{\circ} \mathrm{C}$ with $2 \mathrm{M} \mathrm{HCl}$ gave the best results, however this method would probably not be suitable for vegetables, which have high concentrations of thermolabile compounds. The validated method reported here represents a simple and rapid technique for simultaneous determination of two flavonol aglycones. This method is also accurate, where the percentage of recovery is within $98.07-102.15 \%$ and $97.92-101.83 \%$ for quercetin and kaempferol, respectively. The precision of the method is confirmed by the low RSD of replicate injections of quercetin and kaempferol. The method shows a good separation of quercetin and kaempferol from other compounds in broccoli sample with a good resolution. Low LOD and LOQ of quercetin and kaempferol enable the detection and quantitation of these flavonoids in broccoli at low concentrations. In conclusion, this paper shows a useful method to estimate, accurately and precisely, both quercetin and kaempferol in broccoli. 
Table 4. Recovery study of quercetin and kaempferol from broccoli $(n=3)$

\begin{tabular}{|c|c|c|c|c|c|c|c|c|}
\hline \multirow{2}{*}{ Flavonoids } & \multirow{2}{*}{$\begin{array}{c}\text { Quantity } \\
\text { in sample }(\mu \mathrm{g})\end{array}$} & \multirow{2}{*}{$\mathrm{SD}$} & \multirow{2}{*}{$\begin{array}{c}\text { Standard } \\
\text { added } \\
(\mu g)\end{array}$} & \multicolumn{3}{|c|}{ Recovery $(\mu \mathrm{g})$} & \multirow{2}{*}{$\begin{array}{c}\text { Recovery } \\
(\%)\end{array}$} & \multirow{2}{*}{$\operatorname{RSD}(\%)$} \\
\hline & & & & Expected & Actual & $\mathrm{SD}$ & & \\
\hline \multirow{3}{*}{ Quercetin } & 356.70 & 4.20 & 285.00 & 641.70 & 629.32 & 7.86 & 98.07 & 1.24 \\
\hline & 356.70 & 4.20 & 355.00 & 711.70 & 702.87 & 5.03 & 98.80 & 0.71 \\
\hline & 356.70 & 4.20 & 430.00 & 786.70 & 803.64 & 6.99 & 102.15 & 0.87 \\
\hline \multirow{3}{*}{ Kaempferol } & 279.50 & 2.37 & 225.00 & 504.50 & 494.00 & 5.09 & 97.92 & 1.03 \\
\hline & 279.50 & 2.37 & 280.00 & 559.50 & 569.74 & 5.82 & 101.83 & 1.02 \\
\hline & 279.50 & 2.37 & 335.00 & 614.50 & 608.50 & 7.12 & 99.02 & 1.17 \\
\hline
\end{tabular}

Table 5. Intra- and inter-day precision of HPLC assay of quercetin and kaempferol

\begin{tabular}{cccccc}
\hline $\begin{array}{c}\text { Concentration } \\
\mu \mathrm{g} \cdot \mathrm{ml}^{-1}\end{array}$ & $\begin{array}{c}\text { Day 1 peak area } \\
(\mathrm{mV} \mathrm{s})\end{array}$ & $\begin{array}{c}\text { Day 2 peak area } \\
(\mathrm{mV} \mathrm{s})\end{array}$ & $\begin{array}{c}\text { Day 3 peak area } \\
(\mathrm{mV} \mathrm{s})\end{array}$ & $\begin{array}{c}\text { Intra-day RSD } \\
\%\end{array}$ & $\begin{array}{c}\text { Inter-day RSD } \\
\%\end{array}$ \\
\hline $\begin{array}{c}\text { Quercetin } \\
1.25\end{array}$ & 220.5 & 223.04 & 219.02 & 0.47 & 0.92 \\
2.50 & 440 & 435.33 & 429.52 & 0.38 & 1.21 \\
5.00 & 943 & 933.98 & 924.66 & 0.79 & 0.98 \\
10.00 & 1081 & 1064.57 & 1051.61 & 1.02 & 1.38 \\
\hline Kaempferol & & & & & \\
1.08 & 113.88 & 110.37 & 109.85 & 0.36 & 1.97 \\
2.15 & 220.88 & 217.86 & 214.74 & 0.57 & 0.41 \\
4.30 & 447.37 & 439.35 & 441 & 0.62 & 0.96 \\
10.80 & 1102.20 & 1081.64 & 1112.78 & 0.51 & 1.44 \\
\hline
\end{tabular}

\section{REFERENCES}

Australian Pesticides \& Veterinary Medicines Authority (APVMA). Guidelines for the validation of analytical methods for active constituent, agricultural and veterinary chemical products. October 2004.

De Rijke E., Out P., Niessen W.M.A., Ariese F., Gooijer C., Brinkman U.A.T. 2006. Analytical separation and detection methods for flavonoids. J. Chromatogr. A 1112: 31-63. DOI: 10.1016/j.chroma.2006.01.019.

Dixon R., Paiva N. 1995. Stress-induced phenylpropanoid metabolism. Plant Cell 7: 1085-1097. DOI: $10.1105 /$ tpc.7.7.1085.

Duthie G., Crozier A. 2000. Plant derived phenolic antioxidants. Curr. Opin. Lipidol. 11: 43-47.

Erlund I. 2004. Review of the flavonoids quercetin, hesperetin, and naringenin. Dietary sources, bioactivities, bioavailability, and epidemiology. Nutr. Res. 24: 851-874. DOI: 10.1016/j.nutres.2004.07.005.
Gliszczyńska-Świgło A., Ciska E., Pawlak-Lemańska K., Chmielewski J., Borkowski T., Tyrakowska B. 2006. Changes in the content of health-promoting compounds and antioxidant activity of broccoli after domestic processing. Food Addit. Contam. 23(11): 1088-1098. DOI: 10.1080/02652030600887594.

Hertog M.G.L., Hollman P.C.H., Venema D.P. 1992. Optimization of a quantitative HPLC determination of potentially anticarcinogenic flavonoids in vegetables and fruits. J. Agric. Food Chem. 40: 1591-1598.

Horbowicz M. 1999. Changes of flavonols content in onion during the vegetation period and storage. Veget. Crops Res. Bull. 50: 81-91.

International Conference on Harmonization (ICH). "Validation of Analytical Procedures PA/PH/OMCL (05) 47 DEF”, elaborated by OMCL Network/EDQM of the Council of Europe; June 2005. 
Koh E., Wimalasiri K.M.S., Chassy A.W., Mitchell A.E. 2009. Content of ascorbic acid, quercetin, kaempferol and total phenolics in commercial broccoli. J. Food Com. Anal. 22: 637-643. DOI: 10.1016/j.jfca.2009.01.019.

Manach C., Mazur A., Scalbert A. 2005. Polyphenols and prevention of cardiovascular diseases. Curr. Opin. Lipidol. 16: 77-84. DOI: 10.1097/00041433-200502000-00013.

Merken H.M., Beecher G.R. 2000. Liquid chromatographic method for the separation and quantification of prominent flavonoid aglycones. J. Chromatogr. A 897: 177-184. DOI: 10.1016/S0021-9673(00)00826-8.

Middleton E. Jr., Kandaswami C., Theoharides T.C. 2000. The effects of plant flavonoids on mammalian cells: implications for inflammation, heart disease, and cancer. Pharmacol. Rev. 52(4): 673-751.

Nijveldt R.J., van Nood E., van Hoorn D.E.C., Boelens P.G., van Norren K., van Leeuwen P.A.M. 2001. Flavonoids: a review of probable mechanisms of action and potential applications. Am. J. Clin. Nutr. 74: 418-425.

Nuutila A.M., Kammiovirta K., Oksman-Caldentey K.M. 2002. Comparison of methods for the hydrolysis flavonoids and phenolic acids from onion and spinach for HPLC analysis. Food Chem. 76(4): 519-525. DOI: 10.1016/S0308-8146(01)00305-3.

Patil B.S., Pike L.M., Yoo K.S. 1995. Variation in the quercetin content in different colored onions (Allium cepa L.). J. Am. Soc. Hort. Sci. 120(6): 909-913.

Perez-Vizcaino F., Bishop-Bailley D., Lodi F., Duarte J., Cogolludo A., Moreno L., Bosca L., Mitchell J.A., Warner T.D. 2006. The flavonoid quercetin induces apoptosis and inhibits JNK activation in intimal vascular smooth muscle cells. Biochem. Biophys. Res. Commun. 346(3): 919-925.

Pietta P.G. 2000. Flavonoids as antioxidants. J. Nat. Prod. 63(7): 1035-1042. DOI: 10.1021/np9904509.

Price K.R., Casuscelli F., Colquhoun I.J., Rhodes M.J.C. 1998. Composition and content of flavonol glycosides in broccoli florets (Brassica oleracea) and their fate during cooking. J. Sci. Food Agr. 77(4): 468-472.

Repollés C., Herrero-Martinez J.M., Ràfolds C. 2006. Analysis of prominent flavonoid aglycones by high-performance liquid chromatography using a monolithic column. J. Chromatogr. A 1131: 51-57. DOI: 10.1016/j.chroma.2006.07.012.
Robards K. 2003. Strategies for the determination of bioactive phenols in plants, fruit and vegetables. J. Chromatogr. A 1000(1-2): 657-691. DOI: 10.1016/S0021-9673(03)00058-X.

Rodríguez-Delgado M.A., Malovaná S., Pérez J.P., Borges T., García Montelongo F.J. 2001. Separation of phenolic compounds by high-performance liquid chromatography with absorbance and fluorimetric detection. J. Chromatogr. A 912(2): 249257. DOI: 10.1016/S0021-9673(01)00598-2.

Rossi M., Garavello W., Talamini R., La Vecchia C., Franceschi S., Lagiou P., Zambon P., Dal Maso L., Bosetti C., Negri E. 2007. Flavonoids and risk of squamous cell esophageal cancer. Int. J. Cancer. 120(7): 1560-1564. DOI: 10.1002/ijc.22499.

Roy M.K., Juneja L.R., Isobe S., Tsushida T. 2009. Steam processed broccoli (Brassica oleracea) has higher antioxidant activity in chemical and cellular assay systems. Food Chem. 114(1): 263-269. DOI: 10.1016/j.foodchem.2008.09.050.

Schieber A., Keller P., Carle R. 2001. Determination of phenolic acids and flavonoids of apple and pear by high-performance chromatography. J. Chromatogr. A 910(2): 265-273. DOI: 10.1016/S0021-9673(00)01217-6.

Schroeter H., Heiss C., Balzer J., Kleinbongard P., Keen C.L., Hollenberg N.K., Sies H., Kwik-Uribe C., Schmitz H., Kelm M. 2006. (-)-Epicatechin mediates beneficial effects of flavonol-rich cocoa on vascular function in humans. Proc. Natl. Acad. Sci. USA 103(4): 1024-1029. DOI: 10.1073/pnas.0510168103.

Sellappan S., Akoh C.C. 2002. Flavonoids and antioxidant capacity of Georgia-grown Vidalia onions. J. Agric. Food Chem. 50(19): 5338-5342. DOI: 10.1021/jf020333a.

Sousa de Brito E., Pessanha de Araújo M.C., Lin L.Z., Harnly J. 2007. Determination of the flavonoid components of cashew apple (Anacardium occidentale) by LC-DAD-ESI/MS. Food Chem. 105(3): 1112-1118. DOI: 10.1016/j.foodchem.2007.02.009.

Steinmetz K.A., Potter J.D. 1996. Vegetables, fruit, and cancer prevention: a review. J. Am. Diet. Assoc. 96(10): 1027-1039. DOI: 10.1016/S0002-8223(96)00273-8.

Vallejo F., Tomás-Barberán F.A., García-Viguera C. 2003. Health-promoting compounds in broccoli as influenced by refrigerated transport and retail sale period. J. Agric. Food Chem. 51(10): 30293034. DOI: $10.1021 /$ jf021065j. 
Vallejo F., Tomás-Barberán F.A., García-Viguera C. 2002. Potential bioactive compounds in health promotion from broccoli cultivars grown in Spain. J. Sci. Food Agric. 82(11): 1293-1297. DOI: 10.1002/jsfa.1183.

Van Acker S.A.B.E., Tromp M.N.J.L., Haenen G.R.M.M., van der Vijgh W.J.F., Bast A. 1995. Flavonoids as scavengers of nitric oxide radical. Biochem. Biophys. Res. Commun. 214(3): 755-759.
Zu Y., Li C., Fu Y., Zhao C. 2006. Simultaneous determination of catechin, rutin, quercetin, kaempferol and isorhamnetin in the extract of sea buckthorn (Hippophae rhamnoides L.) leaves by RP-HPLC with DAD. J. Pharm. Biomed. Anal. 41(3): 714719. DOI: 10.1016/j.jpba.2005.04.052. 